\title{
The effects of a 30-month dietary intervention on bone mineral density: The Postmenopausal Health Study
}

\author{
George Moschonis ${ }^{1}$, Ioanna Katsaroli ${ }^{1}$, George P. Lyritis ${ }^{2}$ and Yannis Manios ${ }^{1}$ * \\ ${ }^{1}$ Department of Nutrition \& Dietetics, Harokopio University of Athens, Athens, Greece \\ ${ }^{2}$ Laboratory for the Research of the Musculoskeletal System, School of Medicine, University of Athens, Athens, Greece
}

(Received 17 June 2009 - Revised 11 January 2010 - Accepted 12 January 2010 - First published online 7 April 2010)

Low dietary Ca intake and vitamin D insufficiency have been implicated as part of the aetiology leading to osteoporosis. The aim of the present study was to examine the effects of a 30-month dietary intervention that combined supplementation of dairy products fortified with Ca and vitamin $\mathrm{D}_{3}$ and lifestyle and nutrition counselling sessions on bone mineral density (BMD) of postmenopausal women. Sixty-six postmenopausal women (aged 55-65 years) were randomised into a dietary group (DG; $n$ 35), receiving daily and for the first 12 months $1200 \mathrm{mg} \mathrm{Ca}$ and 7.5 $\mu \mathrm{g}$ vitamin $\mathrm{D}_{3}$, while for the next 18 months of intervention $1200 \mathrm{mg}$ Ca and $22.5 \mu \mathrm{g}$ vitamin $\mathrm{D}_{3}$ through fortified dairy products, and a control group (CG; $\left.n 31\right)$ receiving neither counselling nor dairy products. The DG was found to have more favourable changes in arms $(P<0 \cdot 001)$, total spine $(P=0 \cdot 001)$ and total body BMD $(P<0.001)$ compared with the CG. Furthermore, a significant increase was observed for the DG in lumbar spine BMD $(0.056 ; 95 \%$ CI 0.009 , $0 \cdot 103)$, which was not found to differentiate significantly compared with the change observed in the $\mathrm{CG}(P=0 \cdot 075)$. In conclusion, the present study showed that intakes of vitamin D of about $22.5 \mu \mathrm{g} / \mathrm{d}$ and of Ca close to the recommended level of $1200 \mathrm{mg}$ from fortified dairy foods for $30 \mathrm{months}$, with compliance ensured by lifestyle and nutrition counselling sessions, can induce favourable changes in arms, total spine and total body BMD of postmenopausal women.

Bone mass: Calcium and vitamin D: Fortified milk

Osteoporosis and fracture risk occur most commonly among middle-aged and older postmenopausal women. These disorders account for a significant burden of morbidity and mortality worldwide and have become a major public health problem nowadays ${ }^{(1)}$. Several dietary and pharmaceutical intervention studies have been implemented so far aiming at minimising bone loss in postmenopausal women ${ }^{(1-18)}$. Regarding dietary interventions, the most common approach is the supplementation of $\mathrm{Ca}$ and vitamin $\mathrm{D}_{3}$, while as far as pharmaceutical interventions are concerned, the usual practice includes hormone replacement therapy regimens, biphosphonates, selective oestrogen-receptor modulators and calcitonin ${ }^{(1)}$.

The effectiveness of these interventions is usually assessed by changes in biochemical indices of bone turnover and calciotropic hormones, but primarily by changes in bone mineral density (BMD) $)^{(1,2,4,5,10,11,13-15,18)}$. Measurement of BMD with dual-energy X-ray absorptiometry (DXA) is considered the 'gold standard' technique, and is widely used in clinical practice for fracture risk discrimination and/or prediction, for the diagnosis of osteoporosis and for monitoring skeletal status changes, mainly due to its relatively high reproducibility and longitudinal sensitivity ${ }^{(19,20)}$.

Adequate intake of certain nutrients essential for bone metabolism, such as $\mathrm{Ca}$ and vitamin $\mathrm{D}$, plays an important role in maintaining bone mass. With increasing age, however, both dietary $\mathrm{Ca}$ intake and intestinal $\mathrm{Ca}$ absorption decrease $^{(21)}$. Furthermore, in the elderly serum levels of 25-hydroxy-vitamin $\mathrm{D}_{3}$ decline, mostly due to decreased sunlight (UVB radiation) exposure, which leads to limited capacity for cutaneous vitamin D synthesis ${ }^{(22)}$. All these combined with low dietary intake of vitamin D from staple foods, especially in countries without mandatory fortification policy ${ }^{(23)}$, contribute to lower serum levels of 25-hydroxyvitamin $\mathrm{D}_{3}$ and consequently to accelerated bone loss and increased risk for bone fracture ${ }^{(15,24)}$. It has been reported that meeting daily dietary requirements of $\mathrm{Ca}$ and vitamin $\mathrm{D}$ produces a significant reduction in the incidence of bone fracture $^{(25,26)}$. Furthermore, new evidence suggests that dietary vitamin D intake should considerably increase ${ }^{(26,27)}$, especially in susceptible population groups (i.e. postmenopausal women), due to a high prevalence of vitamin $\mathrm{D}$ deficiency reported even for countries with adequate sunlight exposure ${ }^{(28-30)}$.

The aim of the present study was to examine the changes in BMD at different skeletal sites in apparently healthy, self-dependent postmenopausal women throughout an intervention period of 30 months. During this period the study participants received daily three portions of dairy products (milk and yogurt) fortified with $\mathrm{Ca}$ and vitamin $\mathrm{D}_{3}$. After the first 12 months of intervention the amount of vitamin $\mathrm{D}_{3}$ supplemented to the postmenopausal women via the fortified dairy products increased from $7.5 \mu \mathrm{g} / \mathrm{d}$ to $22.5 \mu \mathrm{g} / \mathrm{d}$ while $\mathrm{Ca}$ intake remained unchanged at $1200 \mathrm{mg} / \mathrm{d}$ throughout the intervention period. To ensure compliance with

Abbreviations: BMD, bone mineral density; CG, control group; DG, dietary group; DXA, dual-energy X-ray absorptiometry.

* Corresponding author: Dr Yannis Manios, fax +30210 9514759, email manios@hua.gr 
the intervention scheme lifestyle and nutrition counselling sessions were further delivered to them on a biweekly basis.

\section{Experimental methods}

\section{Sampling}

First screening. In July 2004 volunteers were invited to participate by informational brochures and posters distributed in public buildings and community centres in three municipalities within the wider district of Athens, namely Nea Smyrni, Kallithea and Neo Iraklio. Through this initial screening, conducted in the premises of the aforementioned settings and with the cooperation of the local authorities, a sample of 307 Greek postmenopausal women volunteered to participate. The first screening comprised a short questionnaire primarily focusing on gathering information on women's medical history, demographic data, dietary intake, physical activity and smoking habits. Furthermore, bone status of all volunteers was assessed by calcaneal quantitative ultrasound measurements, carried out by the SAHARA Clinical Bone Sonometer (Hologic, Inc., Waltham, MA, USA) ${ }^{(31)}$. Through this initial screening those women diagnosed having a T-score lower than $-2 \cdot 5$, taking medications (i.e. thiazide diuretics, glucocorticoids) and/or dietary supplements (Ca, $\mathrm{Mg}$, phosphate or vitamin D) that affect bone metabolism, having any kind of degenerative chronic disease (i.e. diabetes, nephrolithiasis, heart disease, cancer, hyper- and hypothyroidism, hyperparathyroidism, impaired renal and liver function), smoking and being menopausal for less than 1 year were excluded from the second screening of the study. The present study was conducted according to the guidelines laid down in the Declaration of Helsinki and all procedures involving human subjects were approved by the Ethics Committee of Harokopio University of Athens. Written informed consent was obtained from all subjects.

Second screening. After the initial screening ninety-six women (aged 55-65 years) satisfying the inclusion criteria were identified and were invited to participate at the second screening of the study. During the second screening all volunteers underwent a DXA measurement (Lunar DPX-MD; Lunar Corp., Madison, WI, USA), as well as haematological and biochemical examinations, comprising haematological profile, erythrocyte sedimentation rate and serum $\mathrm{Ca}, \mathrm{P}$, glutamicoxaloacetic and glutamic pyruvic transaminases, alkaline phosphatase and creatinine levels. Those women found to be osteoporotic, according to the data provided by the DXA examination, or having abnormal values on the aforementioned blood indices, were excluded from the study. This second screening yielded eighty-two eligible women. The intervention component of the study was initiated in October 2004.

\section{Study groups}

These eighty-two eligible women were randomly assigned to a dietary group (DG) and a control group (CG) using a table of random digits. The DG consisted of forty-two women, who were advised to consume three portions of low-fat dairy products fortified with $\mathrm{Ca}$ and vitamin $\mathrm{D}_{3}$ (milk and yogurt) on a daily basis. Subjects in the CG comprised forty women, to whom no intervention was delivered as they continued with their usual diet throughout the intervention period of 30 months. The sample sizes in the two groups were adequate since we achieved statistical power greater than $90 \%$ for standardised differences for the main outcomes of the present study (i.e. BMD indices) between groups greater than 2.5 (SE 1.4) with a probability of type I error $<0.05$.

Of the eighty-two women initially assigned to participate in the study, sixteen could not be re-examined at the 30-month follow-up examination, providing a total of sixty-six women with full data from all examinations. Of these sixteen subjects, seven from the DG dropped out due to personal reasons, whereas nine subjects from the CG either could not be tracked down or were not available to participate at the follow-up examinations. Consequently the number of subjects in each group with full baseline and follow-up data was thirty-five for the DG and thirty-one for the CG. The mean age of these women was 60.0 (SD 4.8) years (age range 55-65 years) and the average time since their menopause was 9.5 (SD 6.3) years.

To ensure compliance to the intervention scheme, lifestyle and nutrition counselling sessions were held biweekly within the settings of the University. In brief, the counselling part of the study was based on a combined application of the Health Belief Model $^{(32)}$ and the Social Cognitive Theory ${ }^{(33)}$ and was aiming to increase subjects' awareness on health issues, primarily related to osteoporosis, but also to improve their self-efficacy in adopting healthier lifestyle and dietary patterns. The sessions covered seven topics on health and nutrition issues and most of those were held more than once. More specifically, the first sessions primarily focused on educating the subjects on the pathophysiology of osteoporosis as well as the risk factors (health-related behaviours) related to its development. Gradually the sessions became more interactive and emphasis was given in guiding and assisting the subjects in changing their dietary and physical activity habits. More information about the theoretical framework and analytical content of these sessions is presented elsewhere ${ }^{(34)}$.

In order to avoid excess energy intake, subjects in the DG were also advised to substitute other dairy products in their diet with those provided. The dairy products given to the DG subjects at the biweekly sessions were enriched with $\mathrm{Ca}$, providing a total of $400 \mathrm{mg}$ Ca per portion (one portion equals to $250 \mathrm{ml}$ milk and to $200 \mathrm{~g}$ yogurt). The extra Ca source was concentrated milk protein, which is a natural source of milk $\mathrm{Ca}$. Regarding the vitamin D content of the fortified dairy products, after the first 12 months of intervention the vitamin $\mathrm{D}_{3}$ content of the milk portion increased from $2.5 \mu \mathrm{g}$ to $10 \mu \mathrm{g}$, while the vitamin $\mathrm{D}$ content of the yogurt products remained the same (i.e. $2.5 \mu \mathrm{g}$ per portion). This led to a total daily supplementation of $22.5 \mu \mathrm{g}$ vitamin $\mathrm{D}_{3}$ to the $\mathrm{DG}$ subjects through the consumption of two portions of milk and one portion of yogurt. Regarding compliance to the intervention scheme, this was assessed via information obtained at the biweekly sessions, combined with data obtained from the nutritional assessments conducted at baseline and follow-up examinations. These data showed that the compliance to the intervention scheme was reaching a rate of 93 (range 89-100)\%.

\section{Assessment of the effectiveness of the intervention}

During the intervention period the subjects from all study groups were invited to go through certain examinations 
primarily focusing on the assessment of behavioural and clinical indices. The data obtained from the second screening of the study were used as baseline data. Follow-up examinations were conducted after 5, 12, 24 and 30 months of intervention at March 2005, September-October 2005, September-October 2006 and March 2007, respectively. At baseline and follow-up examinations the following measurements were obtained.

Anthropometric measurements. Anthropometry was carried out during the initial screening, as well as at baseline and at all follow-up examinations. In all aforementioned time points body weight and standing height were measured in light clothing and with no shoes using a digital scale (Seca Alpha, model 770; Seca, Hamburg, Germany) with an accuracy of $\pm 100 \mathrm{~g}$ and a commercial stadiometer (Leicester Height Measure; Invicta Plastics Ltd, Oadby, Leics, UK) to the nearest $0.5 \mathrm{~cm}$, respectively. BMI was calculated as weight $(\mathrm{kg})$ divided by height squared $\left(\mathrm{m}^{2}\right)$.

Nutritional assessment. At baseline, mid-term and final examinations the $24 \mathrm{~h}$ recall technique was used to collect dietary intake information for a total of $3 \mathrm{~d}$, two weekdays and one weekend day, most preferably Sunday. All interviewers were rigorously trained to minimise interviewer effects. Respondents were asked to recall the type and amount of any food and beverage consumed during the previous day in a chronological order, i.e. from the time they woke up in the morning to the same time the following day. To improve the accuracy of food descriptions and portion sizes, standard household measures (cups, tablespoons, etc) and picture food models (Western Dairy Council, Thornton, CO, USA) were used during interviews to define amounts when appropriate. Food intake data were analysed using the Nutritionist V diet analysis software (First Databank, San Bruno, CA, USA), which was extensively amended to include Food Composition Tables for Greek foods and recipes ${ }^{(35,36)}$ and chemically analysed commercial food items widely consumed in Greece.

Physical activity assessment. Assessment of physical activity was made by a $3 \mathrm{~d}$ activity interview questionnaire. Respondents reported the time spent on various physical activities during two consecutive weekdays and one weekend day. The questionnaire classified all work, sport and leisure activities into four categories, on the basis of their average intensity relative to the impact on the cardiovascular system (low to high), and also by subgrouping activities according to their impact on bone mass (low to high) ${ }^{(37)}$. The aim of the questionnaire was to determine the frequency and duration ( $\mathrm{h} / \mathrm{session})$ that subjects devoted weekly in these physical activity categories. The total amount of time devoted weekly on activity categories having intensity higher than 4 metabolic equivalents was defined as time spent on moderate-to-vigorous physical activities.

Bone mineral density and total body composition measurements. $\mathrm{BMD}\left(\mathrm{g} / \mathrm{cm}^{2}\right)$ of the lumbar spine (L2-L4) and total body (i.e. total and segmental BMD, lean and fat mass) was measured at baseline, at 12 and at 30 months of follow-up examination, respectively, using DXA (Lunar DPX-MD; Lunar Corp.) with the analysis software version 4.6. The BMD of regional skeletal sites (i.e. arms, legs, pelvis and total spine) was extracted from the analyses of total body scans. The same geometry at repeated measurements of these skeletal sites was accounted for by ensuring correct positioning of each study participant, exactly as indicated in the manufacturer's manual. Furthermore, all follow-up scans were analysed by using the compare-scans mode of the equipment's software in order to define exactly the same profile lines at baseline and follow-up measurement for each subject. A daily quality-assurance check was performed at each time point of the follow-up examination, using a calibration standard of known composition provided by the manufacturer. Before the beginning of the study the $\mathrm{CV}$ were estimated and were found to be $0.7 \%$ for total body $\mathrm{BMD}$ and to range from 1 to $2 \%$ for other regional skeletal sites. The scans were performed in the morning by an experienced technician, who was blinded to the therapy.

\section{Statistical analysis}

All data are reported as mean values and standard deviations, or as mean change and $95 \%$ CI over baseline. The KolmogorovSmirnov test was used to determine the normality of distribution of the examined variables. Differences in baseline characteristics between groups were evaluated by using Student's $t$ test. Repeated-measures ANOVA was used to evaluate the significance of the differences between groups at baseline, 12 and 30 months follow-up (treatment effect), the significance of the changes observed within each group (time effect) and the effect of treatment $\times$ time interaction. The between-group factor was the study groups (i.e. DG v. CG); the within-group factor was the time-point of measurement (i.e. baseline, 12 and 30 months of intervention). All $P$ values reported were two-tailed. Statistical analysis was conducted with the SPSS (version 13.0; SPSS, Inc., Chicago, IL, USA). The level of statistical significance was set at $P \leq 0 \cdot 05$.

\section{Results}

The baseline characteristics of the sixty-six study participants with full data at baseline and follow-up examinations are summarised in Table 1. No differences were observed between the two study groups.

Table 2 summarises the comparisons between groups with respect to the changes observed during the 30-month intervention period in certain behavioural indices related to bone metabolism (i.e. diet and physical activity). Regarding macronutrients, the decrease in total fat intake observed in the DG

Table 1. Baseline differences in demographic and anthropometric indices between the dietary and control groups

(Mean values and standard deviations)

\begin{tabular}{|c|c|c|c|c|c|}
\hline & \multicolumn{2}{|c|}{$\begin{array}{l}\text { Dietary group } \\
\qquad(n 35)\end{array}$} & \multicolumn{2}{|c|}{$\begin{array}{l}\text { Control group } \\
\qquad(n 31)\end{array}$} & \multirow[b]{2}{*}{$P^{\star}$} \\
\hline & Mean & SD & Mean & $\mathrm{SD}$ & \\
\hline Age (years) & $59 \cdot 0$ & $4 \cdot 4$ & $60 \cdot 7$ & $5 \cdot 0$ & 0.103 \\
\hline $\begin{array}{l}\text { Time since menopause } \\
\text { (years) }\end{array}$ & $8 \cdot 6$ & $5 \cdot 8$ & $10 \cdot 2$ & $6 \cdot 6$ & 0.251 \\
\hline Weight (kg) & 71.6 & $9 \cdot 1$ & 73.9 & $12 \cdot 9$ & 0.366 \\
\hline Height (cm) & $158 \cdot 9$ & $6 \cdot 7$ & $156 \cdot 9$ & 5.9 & 0.136 \\
\hline BMI $\left(\mathrm{kg} / \mathrm{m}^{2}\right)$ & $28 \cdot 3$ & $4 \cdot 0$ & $29 \cdot 5$ & $6 \cdot 1$ & 0.302 \\
\hline Fat body mass $(\mathrm{kg})$ & $31 \cdot 2$ & $6 \cdot 8$ & $31 \cdot 8$ & $9 \cdot 2$ & 0.409 \\
\hline Lean body mass $(\mathrm{kg})$ & $37 \cdot 7$ & 3.7 & 38.9 & $4 \cdot 6$ & 0.110 \\
\hline Serum $25(\mathrm{OH}) \mathrm{D}$ & $29 \cdot 1$ & $8 \cdot 6$ & $26 \cdot 2$ & 8.5 & 0.181 \\
\hline Serum PTH & $31 \cdot 6$ & $13 \cdot 2$ & $34 \cdot 2$ & $20 \cdot 7$ & 0.539 \\
\hline
\end{tabular}

25(OH)D, 25-hydroxy-vitamin D; PTH, parathyroid hormone.

${ }^{*}$ Derived from Student's $t$ test. 
Table 2. Changes in dietary intake (energy, and macro- and micronutrients) and physical activity indices for women in the dietary ( $n 35)$ and control ( $n 31)$ groups after 12 and 30 months of intervention (Mean values and standard deviations or mean changes and $95 \%$ confidence intervals)

\begin{tabular}{|c|c|c|c|c|c|c|c|c|c|c|c|}
\hline & \multicolumn{2}{|c|}{ Baseline } & \multicolumn{2}{|c|}{ 12-month follow-up } & \multicolumn{2}{|c|}{ 12-month change } & \multicolumn{2}{|c|}{ 30-month follow-up } & \multicolumn{2}{|c|}{ 30-month change } & \multirow[b]{2}{*}{$P^{*}$} \\
\hline & Mean & SD & Mean & SD & Mean & $95 \% \mathrm{Cl}$ & Mean & SD & Mean & $95 \% \mathrm{Cl}$ & \\
\hline Energy intake (kJ/d) & & & & & & & & & & & 0.512 \\
\hline Control group & $7141 \cdot 2$ & $1837 \cdot 1$ & 6577.9 & $1565 \cdot 4$ & -518.5 & $-51143 \cdot 8,106 \cdot 7$ & $7423 \cdot 6$ & 1691.5 & 452.9 & $-358 \cdot 3,1264 \cdot 2$ & \\
\hline Dietary group & $6675 \cdot 3$ & $1096 \cdot 6$ & $6620 \cdot 1$ & 999.3 & $-97 \cdot 2$ & $-702 \cdot 6,508 \cdot 1$ & $7616 \cdot 8$ & $1410 \cdot 2$ & 781.4 & $-4.0,1566.9$ & \\
\hline$P \dagger$ & \multicolumn{2}{|c|}{0.301} & \multicolumn{2}{|c|}{0.968} & & & \multicolumn{2}{|c|}{0.837} & & & \\
\hline Carbohydrate intake (\% kJ) & & & & & & & & & & & 0.677 \\
\hline Control group & 42.4 & $6 \cdot 3$ & $42 \cdot 8$ & 6.3 & 0.2 & $-3 \cdot 8,4 \cdot 3$ & 43.3 & 8.4 & 0.7 & $-3 \cdot 4,4.8$ & \\
\hline Dietary group & $42 \cdot 4$ & 8.4 & $44 \cdot 3$ & $5 \cdot 1$ & $2 \cdot 0$ & $-1 \cdot 8,5 \cdot 9$ & 44.4 & $8 \cdot 1$ & $2 \cdot 2$ & $-1 \cdot 6,6 \cdot 1$ & \\
\hline$P \dagger$ & \multicolumn{2}{|c|}{0.983} & \multicolumn{2}{|c|}{0.225} & & & \multicolumn{2}{|c|}{0.476} & & & \\
\hline Total fat intake (\% kJ) & & & & & & & & & & & 0.043 \\
\hline Control group & $36 \cdot 2$ & 4.7 & 34.5 & 6.5 & -1.5 & $-4 \cdot 7,1 \cdot 7$ & $36 \cdot 2$ & 7.9 & 0.2 & $-3 \cdot 7,4 \cdot 1$ & \\
\hline Dietary group & $35 \cdot 2$ & $6 \cdot 6$ & $30 \cdot 6$ & 3.8 & -4.8 & $-7 \cdot 8,-1 \cdot 8$ & $31 \cdot 7$ & 7.5 & -3.7 & $-7.4,-0.02$ & \\
\hline$P \dagger$ & \multicolumn{2}{|c|}{0.504} & \multicolumn{2}{|c|}{0.002} & & & \multicolumn{2}{|c|}{0.014} & & & \\
\hline Protein intake (\% kJ) & & & & & & & & & & & 0.426 \\
\hline Control group & $21 \cdot 3$ & $3 \cdot 8$ & $22 \cdot 7$ & $2 \cdot 7$ & $1 \cdot 3$ & $-1 \cdot 1,3 \cdot 7$ & $20 \cdot 4$ & $6 \cdot 5$ & -0.9 & $-4 \cdot 3,2 \cdot 5$ & \\
\hline Dietary group & 22.5 & 4.5 & $25 \cdot 1$ & 3.8 & $2 \cdot 8$ & $0.4,5 \cdot 1$ & 23.9 & $6 \cdot 0$ & 1.5 & $-1 \cdot 7,4 \cdot 7$ & \\
\hline$P \dagger$ & \multicolumn{2}{|c|}{0.342} & \multicolumn{2}{|c|}{0.005} & & & \multicolumn{2}{|c|}{0.038} & & & \\
\hline Ca intake $(\mathrm{mg} / \mathrm{d})$ & & & & & & & & & & & $<0.001$ \\
\hline Control group & 682.9 & $226 \cdot 1$ & $749 \cdot 7$ & 394.7 & 59.5 & $-80 \cdot 2,199 \cdot 3$ & $670 \cdot 7$ & $334 \cdot 2$ & $-6 \cdot 2$ & $-195 \cdot 0,182 \cdot 7$ & \\
\hline Dietary group & 678.6 & $275 \cdot 1$ & 1140.4 & 286.3 & 468.0 & $338.4,597.7$ & $1182 \cdot 8$ & 283.4 & 499.0 & $323 \cdot 8,674 \cdot 2$ & \\
\hline$P \dagger$ & \multicolumn{2}{|c|}{0.924} & \multicolumn{2}{|c|}{$<0.001$} & & & \multicolumn{2}{|c|}{$<0.001$} & & & \\
\hline$P$ intake $(\mathrm{mg} / \mathrm{d})$ & & & & & & & & & & & 0.046 \\
\hline Control group & 948.3 & $303 \cdot 7$ & 1075.5 & 459.7 & $118 \cdot 1$ & $-53 \cdot 0,289 \cdot 2$ & $1090 \cdot 6$ & 484.3 & $156 \cdot 1$ & $-68 \cdot 3,380 \cdot 5$ & \\
\hline Dietary group & 993.5 & $280 \cdot 9$ & 1300.5 & $276 \cdot 1$ & $315 \cdot 3$ & $151 \cdot 6,479 \cdot 1$ & $1409 \cdot 2$ & $626 \cdot 9$ & $403 \cdot 1$ & $188 \cdot 3,617 \cdot 9$ & \\
\hline$P \dagger$ & \multicolumn{2}{|c|}{0.583} & \multicolumn{2}{|c|}{0.011} & & & \multicolumn{2}{|c|}{0.036} & & & \\
\hline Mg intake (mg/d) & & & & & & & & & & & $<0.001$ \\
\hline Control group & $198 \cdot 3$ & $41 \cdot 8$ & $212 \cdot 1$ & 101.9 & $11 \cdot 1$ & $-24 \cdot 3,46 \cdot 5$ & $269 \cdot 4$ & 183.6 & 74.4 & $7 \cdot 0,141 \cdot 9$ & \\
\hline Dietary group & $195 \cdot 4$ & $46 \cdot 6$ & $289 \cdot 4$ & 66.9 & $96 \cdot 2$ & $63 \cdot 9,128 \cdot 5$ & 314.9 & $107 \cdot 9$ & $116 \cdot 7$ & $55 \cdot 1,178 \cdot 2$ & \\
\hline$P \dagger$ & & & & & & & & & & & \\
\hline Vitamin D intake $(\mu \mathrm{g} / \mathrm{d})$ & & & & & & & & & & & $<0.001$ \\
\hline Control group & 0.61 & 0.61 & 1.40 & 1.1 & 0.71 & $-0.32,1.73$ & 1.2 & 0.6 & 0.52 & $-2.46,3.50$ & \\
\hline Dietary group & 0.76 & 1.09 & $5 \cdot 29$ & 1.9 & 4.60 & $3.69,5.51$ & $18 \cdot 8$ & 1.3 & $18 \cdot 15$ & $17.50,18.80$ & \\
\hline$P \dagger$ & & & & & & & & & & & \\
\hline MVPA (min/week) & & & & & & & & & & & 0.868 \\
\hline Control group & $109 \cdot 1$ & 138.5 & 91.5 & $90 \cdot 0$ & $-17 \cdot 6$ & $-83 \cdot 5,48 \cdot 3$ & $108 \cdot 2$ & $53 \cdot 1$ & -0.9 & $-67 \cdot 1,65 \cdot 3$ & \\
\hline Dietary group & $134 \cdot 7$ & $143 \cdot 0$ & $126 \cdot 6$ & $146 \cdot 2$ & -8.1 & $-63 \cdot 5,47 \cdot 3$ & $128 \cdot 7$ & $116 \cdot 4$ & $-6 \cdot 0$ & $-62 \cdot 4,50 \cdot 4$ & \\
\hline $\mathrm{P} \dagger$ & & & & & & & & & & & \\
\hline
\end{tabular}

MVPA, moderate-to-vigorous physical activities.

†Between-group comparisons at baseline, 12 and 30 months (treatment effect). 
Table 3. Changes in bone mineral density (BMD) based on dual-energy X-ray absorptiometry measurements at various skeletal sites for women in the dietary ( $n$ 35) and control ( $n$ 31) groups after 12 and 30 months of intervention

(Mean values and standard deviations or mean changes and $95 \%$ confidence intervals)

\begin{tabular}{|c|c|c|c|c|c|c|c|c|c|c|c|}
\hline & \multicolumn{2}{|c|}{ Baseline } & \multicolumn{2}{|c|}{$\begin{array}{l}\text { 12-month } \\
\text { follow-up }\end{array}$} & \multicolumn{2}{|c|}{ 12-month change } & \multicolumn{2}{|c|}{$\begin{array}{l}\text { 30-month } \\
\text { follow-up }\end{array}$} & \multicolumn{2}{|c|}{ 30-month change } & \multirow[b]{2}{*}{$P^{*}$} \\
\hline & Mean & SD & Mean & SD & Mean & $95 \% \mathrm{Cl}$ & Mean & SD & Mean & $95 \% \mathrm{Cl}$ & \\
\hline Arms BMD $\left(\mathrm{g} / \mathrm{cm}^{2}\right)$ & & & & & & & & & & & $<0.001$ \\
\hline Control group & 0.0849 & 0.089 & 0.810 & 0.093 & -0.041 & $-0.066,-0.015$ & 0.804 & 0.0726 & -0.047 & $-0.077,-0.016$ & \\
\hline Dietary group & 0.830 & 0.079 & 0.809 & 0.073 & -0.020 & $-0.040,-0.001$ & 0.862 & 0.089 & 0.033 & $0.009,0.058$ & \\
\hline$P \dagger$ & \multicolumn{2}{|c|}{0.545} & \multicolumn{2}{|c|}{0.742} & & & \multicolumn{2}{|c|}{0.003} & & & \\
\hline Pelvi.s BMD $\left(\mathrm{g} / \mathrm{cm}^{2}\right)$ & & & & & & & & & & & 0.064 \\
\hline Control group & 1.067 & 0.102 & 1.056 & 0.090 & -0.013 & $-0.033,0.006$ & 1.067 & 0.084 & -0.003 & $-0.034,0.028$ & \\
\hline Dietary group & 1.096 & 0.078 & $1 \cdot 104$ & 0.076 & 0.010 & $-0.006,0.026$ & 1.089 & 0.087 & -0.004 & $-0.029,0.021$ & \\
\hline$P \dagger$ & \multicolumn{2}{|c|}{0.180} & \multicolumn{2}{|c|}{0.014} & & & \multicolumn{2}{|c|}{0.209} & & & \\
\hline Total spine BMD $\left(\mathrm{g} / \mathrm{cm}^{2}\right)$ & & & & & & & & & & & 0.001 \\
\hline Control group & $1 \cdot 139$ & 0.152 & $1 \cdot 104$ & 0.147 & -0.037 & $-0.075,0.001$ & 1.193 & 0.139 & 0.049 & $0.006,0.092$ & \\
\hline Dietary group & 1.119 & 0.124 & $1 \cdot 161$ & 0.135 & 0.043 & $0.013,0.073$ & 1.234 & 0.135 & 0.118 & $0.084,0.153$ & \\
\hline$P \dagger$ & \multicolumn{2}{|c|}{0.613} & \multicolumn{2}{|c|}{0.111} & & & \multicolumn{2}{|c|}{0.186} & & & \\
\hline Legs BMD $\left(\mathrm{g} / \mathrm{cm}^{2}\right)$ & & & & & & & & & & & 0.453 \\
\hline Control group & $1 \cdot 131$ & 0.084 & 1.134 & 0.082 & 0.002 & $-0.012,0.016$ & 1.125 & 0.088 & -0.006 & $-0.022,0.009$ & \\
\hline Dietary group & 1.155 & 0.089 & 1.147 & 0.081 & -0.007 & $-0.019,0.004$ & 1.142 & 0.083 & -0.013 & $-0.025,0.001$ & \\
\hline$P \dagger$ & \multicolumn{2}{|c|}{0.310} & \multicolumn{2}{|c|}{0.511} & & & \multicolumn{2}{|c|}{0.443} & & & \\
\hline Total body BMD $\left(\mathrm{g} / \mathrm{cm}^{2}\right)$ & & & & & & & & & & & $<0.001$ \\
\hline Control group & $1 \cdot 124$ & 0.083 & $1 \cdot 112$ & 0.079 & -0.013 & $-0.022,-0.004$ & $1 \cdot 106$ & 0.078 & -0.020 & $-0.030,-0.009$ & \\
\hline Dietary group & $1 \cdot 134$ & 0.072 & $1 \cdot 148$ & 0.069 & 0.015 & $0.008,0.022$ & $1 \cdot 135$ & 0.067 & 0.003 & $-0.006,0.011$ & \\
\hline$P+$ & \multicolumn{2}{|c|}{0.464} & \multicolumn{2}{|c|}{.033} & & & \multicolumn{2}{|c|}{0.048} & & & \\
\hline
\end{tabular}

* Treatment $\times$ time interaction effect.

†Between-group comparisons at baseline, 12 and 30 months (treatment effect). 
was more favourable compared with the change observed in the CG $(P=0.043)$. Furthermore, the average intake of protein was significantly higher in the DG than the CG both at 12 $(P=0.005)$ and 30 months of intervention $(P=0 \cdot 038)$. Nonetheless, the 30-month change in protein intake was not found to differentiate significantly between the two study groups $(P=0 \cdot 426)$. Similarly no significant differences were observed between groups with respect to the changes in energy and carbohydrate intake. Regarding micronutrients, the DG showed higher increases in $\mathrm{Ca}(P<0.001), \mathrm{P}$ $(P=0.046), \mathrm{Mg}(P<0.001)$ and vitamin $\mathrm{D}(P<0.001)$ intakes, compared with the respective changes observed in the CG. Regarding physical activity, no significant differences were observed between groups in the time spent in moderateto-vigorous physical activities over the intervention period.

According to the data presented in Table 3, at the end of the intervention period the DG was found to have more favourable changes in arms $(P<0.001)$, total spine $(P=0.001)$ and total body BMD $(P<0.001)$ compared with the relative changes observed in the $\mathrm{CG}$, respectively. Furthermore, the increase observed in the DG for lumbar (L2-L4) spine BMD over the 30-month intervention $(0.056,95 \%$ CI $0.009,0.103)$ tended to be significantly higher compared with the decrease observed in the CG $(P=0 \cdot 075)$ (Fig. 1).

\section{Discussion}

The findings of the present study were indicative of the effectiveness of the 30-month dietary intervention programme conducted with osteopenic postmenopausal women to induce certain favourable changes in dietary intake and bone mass indices. Regarding dietary intake of micronutrients and of $\mathrm{Ca}$ in particular (Table 2), this was significantly improved in the DG, since it remained close to the recommended level of $1200 \mathrm{mg} / \mathrm{d}^{(38)}$ throughout the intervention period. Furthermore, the increase in the vitamin D content of the fortified milk from $2.5 \mu \mathrm{g}$ to $10 \mu \mathrm{g}$ per portion after the first 12 months of intervention led to a total daily supplementation of $22.5 \mu \mathrm{g} / \mathrm{d}$ through the consumption of two portions of milk and one portion of yogurt. This increase was mainly ascribed to the results from the first 12 months of intervention that showed that the daily dose of $7.5 \mu \mathrm{g}$ vitamin $\mathrm{D}$ provided to the DG through the fortified dairy products was probably not adequate to counterbalance the reduction of serum



Fig. 1. Changes in lumbar spine bone mineral density (BMD) in the dietary group $(--)$ ) and the control group $(-\square-)$. Values are means. * Mean value was significantly different from that at baseline $(P<0.05)$. There was a treatment $\times$ time interaction effect $(P=0.075)$. 25-hydroxy-vitamin D levels during the winter months ${ }^{(39)}$. In addition, it was based on new emerging scientific evidence suggesting the need of combined supplementation both with $\mathrm{Ca}$ and vitamin D in the order of $1000-1200 \mathrm{mg} \mathrm{Ca}$ and $17 \cdot 5-20 \mu \mathrm{g}$ vitamin $\mathrm{D}$ daily in osteopenic postmenopausal women $^{(23,40,41)}$. The consumption of the fortified dairy products also led to significant increases in $\mathrm{Mg}$ and $\mathrm{P}$ intakes, which are also essential for bone mineralisation ${ }^{(42)}$ and could have equally contributed to the favourable BMD changes observed in the present study. However, other human studies have shown no effect on bone after supplementation of $\mathrm{P}^{(43)}$, while the Women's Health Initiative study has shown that postmenopausal women in the highest quintile of dietary $\mathrm{Mg}$ intake had higher rates of wrist fractures ${ }^{(44)}$ than women in lower quintiles.

As far as physical activity was concerned, no changes were observed between the groups (Table 2), although subjects in the DG were encouraged to increase their daily physical activity levels. Similar studies have also confronted difficulties in motivating middle-aged women already having a sedentary lifestyle to become more active ${ }^{(13,45)}$. Furthermore, the use of a subjective method to assess physical activity levels in the present study (i.e. questionnaires) could also be one of the reasons for the statistically insignificant differences between the two study groups. Utilisation of more objective methods to assess physical activity levels, such as accelerometers, might have been more appropriate in the context of the present study, since this could have provided more reliable and valid recording of the participants' moderate and vigorous physical activities than questionnaires ${ }^{(46)}$.

According to the results derived from the DXA measurements, the findings of the present study revealed more favourable changes over the 30-month intervention period in total body BMD in the DG, compared with the CG (Table 3). In agreement with these findings, Riggs et al. ${ }^{(14)}$ have reported an increase in total body BMD for Caucasian postmenopausal women after a 48-month supplementation of $1600 \mathrm{mg}$ Ca per $\mathrm{d}$. However, other dietary intervention studies conducted with Caucasians or Asians have reported either no change ${ }^{(8)}$ or decreases $^{(4,5,10)}$ in total body BMD after daily supplementation of $1000-1200 \mathrm{mg} \mathrm{Ca}$ and $6-20 \mu \mathrm{g}$ vitamin $\mathrm{D}_{3}$ for 24 and 36 months, respectively. Furthermore, the increase observed in the DG for arms BMD was significantly higher than the decrease observed in the $\mathrm{CG}$ over the 30-month intervention period $(P<0 \cdot 001)$. Nonetheless, no significant differences were found between the groups with respect to legs BMD changes. The BMD of the upper and lower body extremes (i.e. legs and arms BMD) measured in the present study is not directly comparable with the forearm and total hip BMD measured in the majority of other similar studies and this could be considered as a limitation regarding these particular comparisons. Bearing in mind this limitation, the findings of the present study regarding arms and legs BMD changes are in line or in contrast to the forearm and total hip BMD changes reported by other similar intervention studies depending on the race of the subjects measured (i.e. Caucasian or Asian). Precisely, two other long-term dietary intervention studies conducted with Caucasian women showed that daily supplementations of $1500 \mathrm{mg} \mathrm{Ca}$ with $12.5 \mu \mathrm{g}$ vitamin $\mathrm{D}_{3}$ and of $1000 \mathrm{mg} \mathrm{Ca}$ with $20 \mu \mathrm{g}$ vitamin $\mathrm{D}_{3}$ induced a significant ${ }^{(6)}$ and a non-significant decrease in 
total hip $\mathrm{BMD}^{(8)}$, respectively. However, Lau et al. ${ }^{(10)}$ reported a significant increase in total hip BMD after 30 months of intervention in Asian postmenopausal women, reaching total daily intakes of $1200 \mathrm{mg} \mathrm{Ca}$ and $6 \mu \mathrm{g}$ vitamin $\mathrm{D}_{3}$ via fortified dairy products. Contrary to our findings, significant decreases in forearm BMD have been observed for Caucasian postmenopausal women following daily intakes of $1200-1500 \mathrm{mg} \quad \mathrm{Ca}$ with $12 \cdot 5-20 \mu \mathrm{g}$ vitamin $\mathrm{D}_{3}^{(3,6)}$, respectively.

Other interesting findings of the present study were the increases in total and lumbar (L2-L4) spine BMD in the DG during the 30-month intervention period. Particularly, the increase in lumbar spine BMD in the DG compared with the CG, although of borderline significance $(P=0.075)$, could probably indicate that the major skeletal benefits derived from the implemented intervention mainly apply for the trabecular (cancellous) but not for the cortical (compact) bone tissue. Still safer conclusions can be reached only by conducting further clinical research and by applying more sensitive bone scanning techniques to examine the changes in BMD distribution. In any case, the more favourable total and lumbar spine BMD changes observed in the present study for the DG were in line with the findings reported by other similar long-term intervention studies conducted with Caucasian postmenopausal women that reached daily intakes of $1600 \mathrm{mg}$ Ca without any vitamin $\mathrm{D}^{(14,15)} ; 1000-1200 \mathrm{mg}$ Ca with $6-10 \mu \mathrm{g}$ vitamin $\mathrm{D}_{3}^{(15)} ; 1000-1500 \mathrm{mg} \mathrm{Ca}$ with $12.5-14 \mu \mathrm{g}$ vitamin $\mathrm{D}_{3}^{(5,6,11)}$; and $1200 \mathrm{mg}$ Ca with $17.5 \mu \mathrm{g}$ vitamin $\mathrm{D}_{3}^{(5)}$. Contrary to these findings, decreases in lumbar spine BMD were observed for Asian women following dietary intakes of $1000-1200 \mathrm{mg}$ Ca per $\mathrm{d}$ and $6-10 \mu \mathrm{g}$ vitamin $\mathrm{D}_{3}$ per $\mathrm{d}$ for 24 and 36 months, respectively ${ }^{(4,10)}$.

In conclusion, the present intervention programme resulted in a significant increase in the dietary intake of several nutrients essential for bone metabolism, such as $\mathrm{Ca}, \mathrm{Mg}, \mathrm{P}$ and vitamin $\mathrm{D}$ through the consumption of fortified dairy products. In particular, intakes of vitamin $\mathrm{D}$ of about $22.5 \mu \mathrm{g} / \mathrm{d}$ and of $\mathrm{Ca}$ close to the recommended level of $1200 \mathrm{mg}$ from fortified dairy foods for 30 months, with compliance ensured by health and nutrition education sessions, were the main dietary changes that led to the favourable changes in arms, total spine and total body BMD in the examined population of postmenopausal women. These changes, and especially the increase in lumbar spine BMD in the DG compared with the $\mathrm{CG}$, could probably indicate that the major skeletal benefits from the implemented intervention appear to affect the trabecular (cancellous) but not the cortical (compact) bone tissue.

\section{Acknowledgements}

The authors would like to thank Paraskevi Kannelou, dietitian, and Sofia Tanagra, technician, for their valuable contribution in data collection and processing.

The present study was supported by a research grant from Friesland Foods Hellas.

G. M. and Y. M. contributed in the conception and design of the study. All authors contributed to data analysis and interpretation, drafting the article and approving the final version submitted.
Y. M. works as a part-time scientific consultant for Friesland Foods Hellas. G. M., G. P. L. and I. K. have no potential conflict of interest.

\section{References}

1. Hodgson SF, Watts NB, Bilezikian JP, et al. (2003) American Association of Clinical Endocrinologists medical guidelines for clinical practice for the prevention and treatment of postmenopausal osteoporosis: 2001 edition, with selected updates for 2003. Endocr Pract 9, 544-564.

2. Baeksgaard L, Andersen KP \& Hyldstrup L (1998) Calcium and vitamin D supplementation increases spinal BMD in healthy, postmenopausal women. Osteoporos Int 8, 255-260.

3. Chapuy MC, Arlot ME, Duboeuf F, et al. (1992) Vitamin $\mathrm{D}_{3}$ and calcium to prevent hip fractures in elderly women. $N$ Engl J Med 327, 1637-1642.

4. Chee WS, Suriah AR, Chan SP, et al. (2003) The effect of milk supplementation on bone mineral density in postmenopausal Chinese women in Malaysia. Osteoporos Int 14, 828-834.

5. Dawson-Hughes B, Harris SS, Krall EA, et al. (1997) Effect of calcium and vitamin D supplementation on bone density in men and women 65 years of age or older. N Engl J Med 337, 670-676.

6. Engelke K, Kemmler W, Lauber D, et al. (2006) Exercise maintains bone density at spine and hip EFOPS: a 3-year longitudinal study in early postmenopausal women. Osteoporos Int 17, 133-142.

7. Frost ML, Blake GM \& Fogelman I (2001) Changes in QUS and BMD measurements with antiresorptive therapy: a two-year longitudinal study. Calcif Tissue Int 69, 138-146.

8. Hunter D, Major P, Arden N, et al. (2000) A randomized controlled trial of vitamin D supplementation on preventing postmenopausal bone loss and modifying bone metabolism using identical twin pairs. J Bone Miner Res 15, 2276-2283.

9. Krieg MA, Jacquet AF, Bremgartner M, et al. (1999) Effect of supplementation with vitamin $\mathrm{D}_{3}$ and calcium on quantitative ultrasound of bone in elderly institutionalized women: a longitudinal study. Osteoporos Int 9, 483-488.

10. Lau EM, Lynn H, Chan YH, et al. (2002) Milk supplementation prevents bone loss in postmenopausal Chinese women over 3 years. Bone 31, 536-540.

11. Meier C, Woitge HW, Witte K, et al. (2004) Supplementation with oral vitamin $\mathrm{D}_{3}$ and calcium during winter prevents seasonal bone loss: a randomized controlled open-label prospective trial. J Bone Miner Res 19, 1221-1230.

12. Palacios S, Castelo-Branco C, Cifuentes I, et al. (2005) Changes in bone turnover markers after calcium-enriched milk supplementation in healthy postmenopausal women: a randomized, double-blind, prospective clinical trial. Menopause 12, $63-68$.

13. Prince R, Devine A, Dick I, et al. (1995) The effects of calcium supplementation (milk powder or tablets) and exercise on bone density in postmenopausal women. J Bone Miner Res 10, 1068-1075.

14. Riggs BL, O'Fallon WM, Muhs J, et al. (1998) Long-term effects of calcium supplementation on serum parathyroid hormone level, bone turnover, and bone loss in elderly women. J Bone Miner Res 13, 168-174.

15. Storm D, Eslin R, Porter ES, et al. (1998) Calcium supplementation prevents seasonal bone loss and changes in biochemical markers of bone turnover in elderly New England women: a randomized placebo-controlled trial. J Clin Endocrinol Metab 83, 3817-3825.

16. Rosenthall L, Caminis J \& Tenehouse A (1999) Calcaneal ultrasonometry: response to treatment in comparison with dual $\mathrm{X}$-ray absorptiometry measurements of the lumbar spine and femur. Calcif Tissue Int 64, 200-204. 
17. Reid IR, Ames RW, Evans MC, et al. (1995) Long-term effects of calcium supplementation on bone loss and fractures in postmenopausal women: a randomized controlled trial. Am J Med 98, 331-335.

18. Heaney RP, McCarron DA, Dawson-Hughes B, et al. (1999) Dietary changes favorably affect bone remodeling in older adults. J Am Diet Assoc 99, 1228-1233.

19. Fogelman I \& Blake GM (2000) Different approaches to bone densitometry. J Nucl Med 41, 2015-2025.

20. Gluer CC (1999) Monitoring skeletal changes by radiological techniques. J Bone Miner Res 14, 1952-1962.

21. Anonymous (1994) NIH Consensus conference. Optimal calcium intake. NIH Consensus Development Panel on Optimal Calcium Intake. JAMA 272, 1942-1948.

22. Mosekilde L (2005) Vitamin D and the elderly. Clin Endocrinol (Oxf) 62, 265-281.

23. Calvo MS, Whiting SJ \& Barton CN (2005) Vitamin D intake: a global perspective of current status. J Nutr 135, 310-316.

24. Rapuri PB, Kinyamu HK, Gallagher JC, et al. (2002) Seasonal changes in calciotropic hormones, bone markers, and bone mineral density in elderly women. J Clin Endocrinol Metab 87, 2024-2032.

25. Miller GD, Jarvis JK \& McBean LD (2001) The importance of meeting calcium needs with foods. J Am Coll Nutr 20, $168 \mathrm{~S}-185 \mathrm{~S}$.

26. Whiting SJ \& Calvo MS (2005) Dietary recommendations to meet both endocrine and autocrine needs of vitamin D. J Steroid Biochem Mol Biol 97, 7-12.

27. Whiting SJ \& Calvo MS (2005) Dietary recommendations for vitamin D: a critical need for functional end points to establish an estimated average requirement. $J$ Nutr 135, 304-309.

28. Isaia G, Giorgino R, Rini GB, et al. (2003) Prevalence of hypovitaminosis $\mathrm{D}$ in elderly women in Italy: clinical consequences and risk factors. Osteoporos Int 14, 577-582.

29. Gannage-Yared MH, Chemali R, Yaacoub N, et al. (2000) Hypovitaminosis D in a sunny country: relation to lifestyle and bone markers. J Bone Miner Res 15, 1856-1862.

30. van der Wielen RP, Lowik MR, van den Berg H, et al. (1995) Serum vitamin D concentrations among elderly people in Europe. Lancet 346, 207-210.

31. Anonymous (1997) SAHARA Clinical Bone Sonometer. Clinical User's Guide. Waltham, MA: Hologic, Inc.
32. Janz NK \& Becker MH (1984) The Health Belief Model: a decade later. Health Educ $Q$ 11, 1-47.

33. Bandura A, Adams NE \& Beyer J (1977) Cognitive processes mediating behavioral change. J Pers Soc Psychol 35, 125-139.

34. Manios Y, Moschonis G, Katsaroli I, et al. (2007) Changes in diet quality score, macro- and micronutrients intake following a nutrition education intervention in postmenopausal women. J Hum Nutr Diet 20, 126-131.

35. University of Crete (1991) Food Composition Tables (website in Greek). http://nutrition.med.uoc.gr/GreekTables

36. Trichopoulou A (2004) Composition Tables of Foods and Greek Dishes. Athens, Greece: School of Medicine: Department of Hygiene and Epidemiology.

37. Groothausen J, Siemer H, Kemper HCG, et al. (1997) Influence of peak strain on lumbar bone mineral density: an analysis of 15 -year physical activity in young males and females. Pediatr Exerc Sci 9, 159-173.

38. Institute of Medicine Food and Nutrition Board (2001) Dietary Reference Intakes: Applications in Dietary Assessment. Washington, DC: National Academy Press.

39. Manios Y, Moschonis G, Trovas G, et al. (2007) Changes in biochemical indexes of bone metabolism and bone mineral density after a 12-mo dietary intervention program: the Postmenopausal Health Study. Am J Clin Nutr 86, 781-789.

40. Rizzoli R, Boonen S, Brandi ML, et al. (2008) The role of calcium and vitamin $\mathrm{D}$ in the management of osteoporosis. Bone 42, 246-249.

41. Bischoff-Ferrari HA, Willett WC, Wong JB, et al. (2005) Fracture prevention with vitamin D supplementation: a metaanalysis of randomized controlled trials. JAMA 293, 2257-2264

42. Kitchin B \& Morgan SL (2007) Not just calcium and vitamin D: other nutritional considerations in osteoporosis. Curr Rheumatol Rep 9, 85-92.

43. Heaney RP \& Recker RR (1987) Calcium supplements: anion effects. Bone Miner 2, 433-439.

44. Palacios $\mathrm{C}$ (2006) The role of nutrients in bone health, from A to Z. Crit Rev Food Sci Nutr 46, 621-628.

45. Wolff I, van Croonenborg JJ, Kemper HC, et al. (1999) The effect of exercise training programs on bone mass: a meta-analysis of published controlled trials in pre- and postmenopausal women. Osteoporos Int 9, 1-12.

46. Reiser LM \& Schlenk EA (2009) Clinical use of physical activity measures. $J$ Am Acad Nurse Pract 21, 87-94. 